\title{
Characterisation of Residual Stress due to Fillet Rolling on Bolts Made of a Nickel Base Superalloy
}

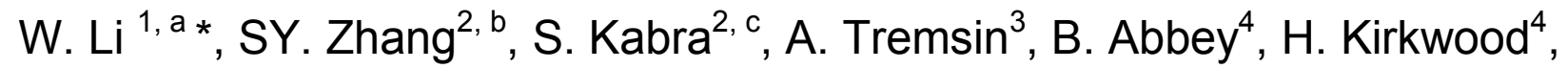

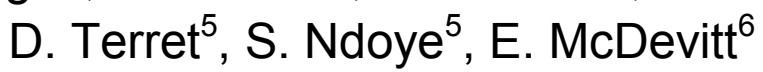 \\ ${ }^{1}$ Rolls-Royce plc., PO Box 31, Moor Lane, Derby DE24 8BJ, UK. \\ ${ }^{2}$ STFC Rutherford Appleton Laboratory, Harwell Oxford, Didcot, Oxfordshire, OX11 0QX, UK. \\ ${ }^{3}$ University of California at Berkeley, Berkeley, CA 94720, USA \\ ${ }^{4}$ La Trobe University, Department of Physics, PS1 Melbourne (Bundoora), Australia \\ ${ }^{5}$ Alcoa Fastening Systems, Toulouse Operation, MECAERO SNC, Boulevard Du Grand Castaing \\ 31128 Portet sur Garonne, France \\ ${ }^{6}$ ATI Allvac 2020 Ashcraft Ave., PO Box 5030, Monroe, NC 28111-5030, USA \\ a wei.li@rolls-royce.com, b shu-yan.zhang@stfc.ac.uk, c saurabh.kabra@stfc.ac.uk
}

Keywords: Fillet rolling, bolt, superalloy, residual stress, neutron diffraction, neutron transmission, hole drilling, 718Plus $®$

\begin{abstract}
:
This paper investigates residual stress due to fillet rolling on bolts made of ATI 718Plus ${ }^{\circledR}$ superalloy. Incremental hole drilling, neutron diffraction and neutron transmission have been used to assess residual stress near the bolt head fillet. A compressive residual stress field was identified in the first $0.5 \mathrm{~mm}$ from the surface. Post fillet rolling solution anneal can relieve the residual stress at the fillet.
\end{abstract}

\section{Introduction}

A bolt underhead fillet is the junction of the cylindrical surface of the bolt shank and the perpendicular surface of the bolt head, which is an area of high stress concentration. Bolts operating in harsh service conditions can fail due to fatigue crack initiated at the fillet [1]. As a result fillet rolling is often used in the bolt manufacturing process to induce compressive residual stress to improve its fatigue resistance. Fig. 1 illustrates a typical set-up for bolt fillet rolling.

As is limited by the geometry of the bolt, residual stress

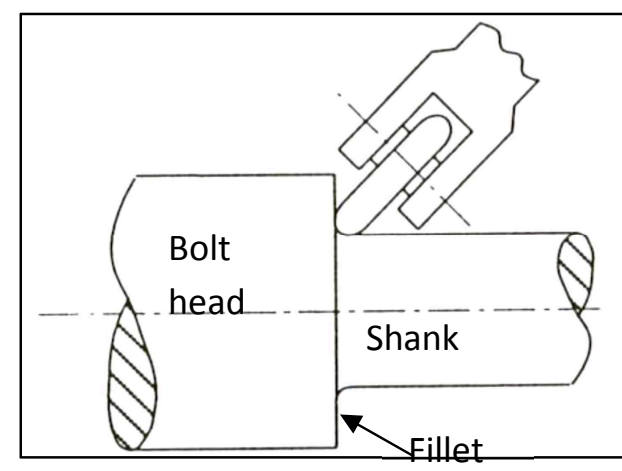

Fig. 1. Schematic of fillet rolling measurement using conventional hole-drilling or laboratory X-ray diffraction is difficult and thus very few data that quantitatively describe the fillet residual stress field have been presented in literature. The present work aims to demonstrate the efficacy of fillet rolling on bolts made in ATI 718 Plus ${ }^{\circledR}$ superalloy by characterising fillet residual stress using neutron diffraction and neutron transmission methods as well as incremental hole drilling technique. The capability of creating 3D strain tomography from the neutron transmission data for genuine engineering components is demonstrated for the first time in literature. 


\section{Experimental procedure}

Material and specimen: The ATI 718Plus ${ }^{\circledR}$ alloy was produced by ATI Allvac from a VIM-VAR heat in a chemical composition to Table I. The material was converted from ingot to $102 \mathrm{~mm}$ square billet through press and GFM, hot rolled to $28 \mathrm{~mm}$ round bars, annealed at $982{ }^{\circ} \mathrm{C}$ with water quench, before being cold drawn to $16 \%$ or $30 \%$ reduction in area, and ground to bars of $12.7 \mathrm{~mm}$ in diameter. The bars were supplied to Alcoa

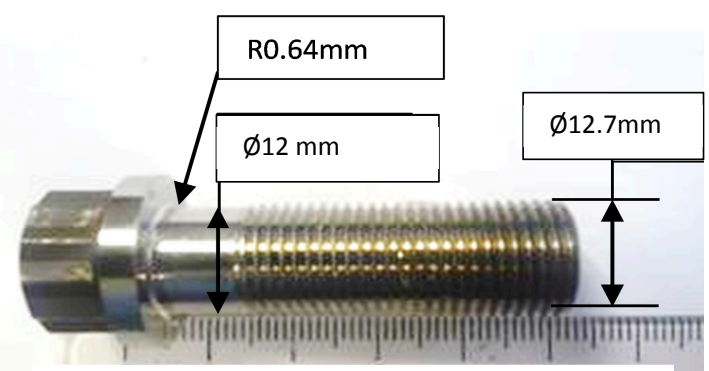

Fig. 2. Major nominal bolt dimensions Fastening System Toulouse Operation to be made into bolts to geometry identical to Society of British Aerospace Companies Standard AS55622. Fig. 2 shows the major nominal bolt dimensions. In this work four parts were supplied in different processing conditions per Table 2 in order to assess the effects of prior and post fillet rolling conditions on residual stress at the fillet. Annealing at $840{ }^{\circ} \mathrm{C}$ for 16 hours for at $950{ }^{\circ} \mathrm{C}$ for 1 hour is expected not only to relieve residual stress but also induce precipitation of $\delta$ phase in the microstructure which may improve the notch sensitivity of the alloy. In fillet rolling operation the bolt flange-shank joint was in contact with the rolling wheels; then a pressure was applied on the bolt head so the bolt could rotate. As the pressure increases, the wheels rolled into the underhead surface until a target load was reached. Then the pressure was maintained at the target load for a given period of time to achieve the desired radius and plastic flow patter.

Table 1. Chemistry in Weight [\%].

\begin{tabular}{|c|c|c|c|c|c|c|c|c|c|}
\hline $\mathbf{C}$ & $\mathbf{C r}$ & $\mathbf{M o}$ & $\mathbf{C o}$ & $\mathbf{T i}$ & $\mathbf{A l}$ & $\mathbf{F e}$ & $\mathbf{N i}$ & $\mathbf{N b}$ & $\mathbf{W}$ \\
\hline 0.02 & 17.9 & 2.7 & 9.0 & 0.7 & 1.5 & 9.3 & 51.7 & 5.5 & 1.0 \\
\hline
\end{tabular}

Table 2. Bolt conditions

\begin{tabular}{|c|c|c|c|c|}
\hline $\begin{array}{c}\text { Bolt } \\
\text { ID }\end{array}$ & $\begin{array}{c}\text { Prior cold } \\
\text { work [\%] }\end{array}$ & Condition & Assessment technique & Objective \\
\hline 1 & 16 & As-forged, no fillet roll & Hole drilling & Stress from forging \\
\hline 2 & 16 & $\begin{array}{c}\text { Fillet rolled \& annealed } \\
\text { (at } 840^{\circ} \mathrm{C} \text { for } 16 \text { hours) }\end{array}$ & $\begin{array}{c}\text { Hole drilling, Neutron } \\
\text { diffraction }\end{array}$ & $\begin{array}{c}\text { Effect of post-rolling } \\
\text { anneal on fillet stress }\end{array}$ \\
\hline 3 & 16 & $\begin{array}{c}\text { Direct aged and fillet } \\
\text { rolled only }\end{array}$ & $\begin{array}{c}\text { Hole drilling, neutron } \\
\text { diffraction, neutron } \\
\text { transmission }\end{array}$ & $\begin{array}{c}\text { Stress from fillet rolling } \\
\text { as the baseline condition }\end{array}$ \\
\hline 4 & 30 & $\begin{array}{c}\left.\text { Annealed (at } 950^{\circ} \mathrm{C} / 1 \mathrm{hr}\right) \\
\text { \& aged, fillet rolled }\end{array}$ & Neutron diffraction & $\begin{array}{c}\text { Stress from fillet rolling } \\
\text { only }\end{array}$ \\
\hline
\end{tabular}

Hole drilling residual stress measurement was carried out at Stresscraft Ltd. As shown in Fig. 3, for each bolt a 031UMG1360 target strain gauge was installed with the target centre at $1.3 \mathrm{~mm}$ from the bolt head face, with element 1 aligned with the axial direction and element 3 in the hoop direction. For each gauge an orbital hole drilling procedure was carried out at 16 drill depth increments, recording the relaxed strains in the two principal directions at each increment. Drilled depth increments were set at $4 \times 16 \mu \mathrm{m}+4 \times 32$ $\mu \mathrm{m}+8 \times 64 \mu \mathrm{m}$, completed in a depth of $704 \mu \mathrm{m}$

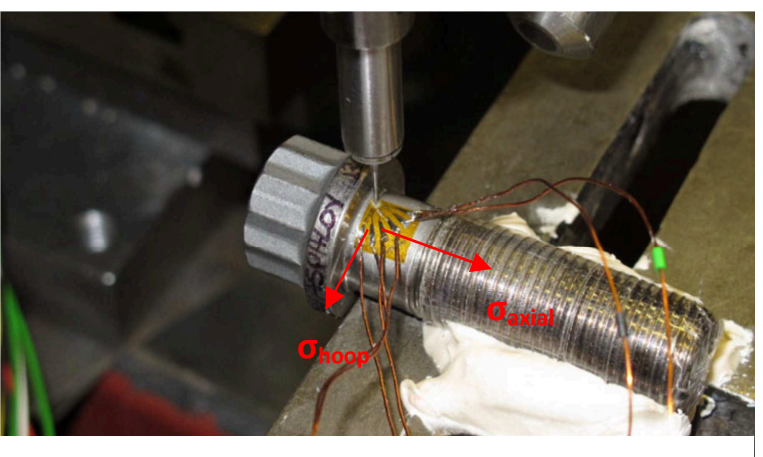

Fig. 3. Arrangement for incremental drilling at target gauge $0.5 \mathrm{~mm}$ from the fillet run-out. to generate residual stress data to depth $512 \mu \mathrm{m}$. Stresses were calculated using Young's modulus of $214 \mathrm{GPa}$ and Poisson's ratio of 0.31 to the Integral Method per NPL Good Practice Guide No. 53 [2]. 
Neutron Diffraction Experiment was carried out on the Engin-X diffractometer at Rutherford Appleton Laboratory, UK. Time-of-flight profiles for the three principal strains: radial, axial and hoop strains, were obtained in the two experimental set-ups as shown in Fig. 4. The slit and collimator were set to create a gauge volume of $1 \times 1 \times 1 \mathrm{~mm}^{3}$, which was located at $0.8 \mathrm{~mm}$ in axial distance from the bolt head flange surface to minimise the attenuation effect of the bolt head. Timeof-flight measurements were carried out with centre of the $1 \mathrm{~mm}$ gauge volume merged at $0.7 \mathrm{~mm}$, $1.0 \mathrm{~mm}$ (for setup $1 \mathrm{only}$ ), $1.3 \mathrm{~mm}$ and $1.6 \mathrm{~mm}$ from the surface of the bolt shank. The strain for all measurement was calculated from the measured lattice spacing $d$ using

$$
\varepsilon_{\text {axial }}=\frac{d-d_{0}}{d_{0}}
$$

Stress-free lattice spacing $\left(\mathrm{d}_{0}\right)$ measurement was conducted at the end face of the threaded section of each of the three bolts. Residual stresses were calculated as follows:

$$
\sigma_{\text {axial }}=\frac{E}{(1+v)(1-2 v)}\left[(1-v) \varepsilon_{\text {axial }}+v\left(\varepsilon_{\text {hoop }}+\varepsilon_{\text {radial }}\right)\right] \text { etc }
$$
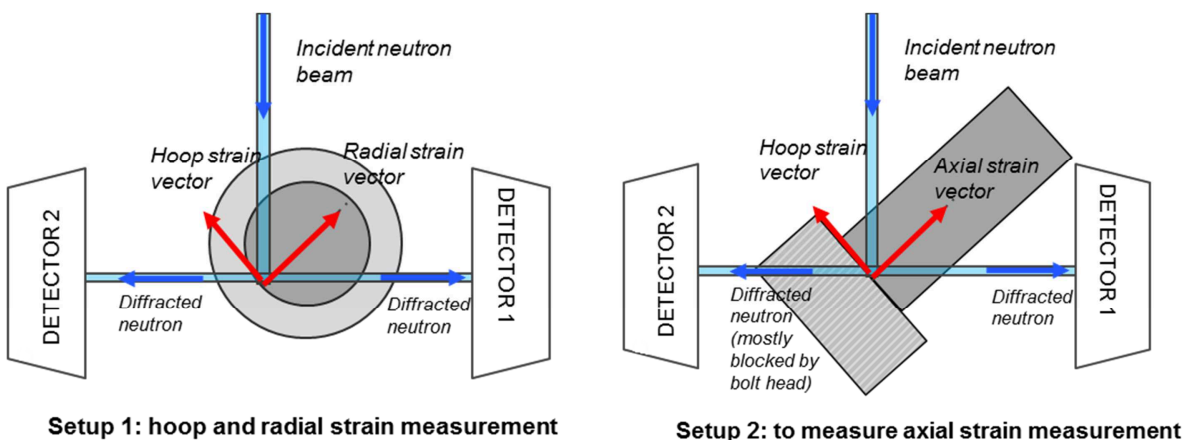

Fig. 4. Sample setup for hoop and radial strain (setup 1) and axial strain (setup 2) measurements.

Due to the relatively small gauge volume and long path length, the statistics of the data was poor and thus only the fundamental (111) peak was fitted in analysis. To understand the effect of the $\gamma^{\prime} / \gamma$ lattice anisotropy on the (111) peak, a separate calibration measurement was carried out in-situ on a tensile specimen machined from a finished bolt. The specimen was incrementally loaded to different macrostrain levels to measure the (111) lattice peak at this strain. Fig. 5 shows that the macrostrain can be linearly correlated with the measured (111) lattice strain. The macrostrain calibration test also reveals that the uniaxial plastic strain can be correlated to the FWHM of the diffraction peak. Fig. 6 shows that the best-defined FWHM correlation is still on the (111) peak. Therefore the FWHM of the (111) peak is used for plastic work assessment.

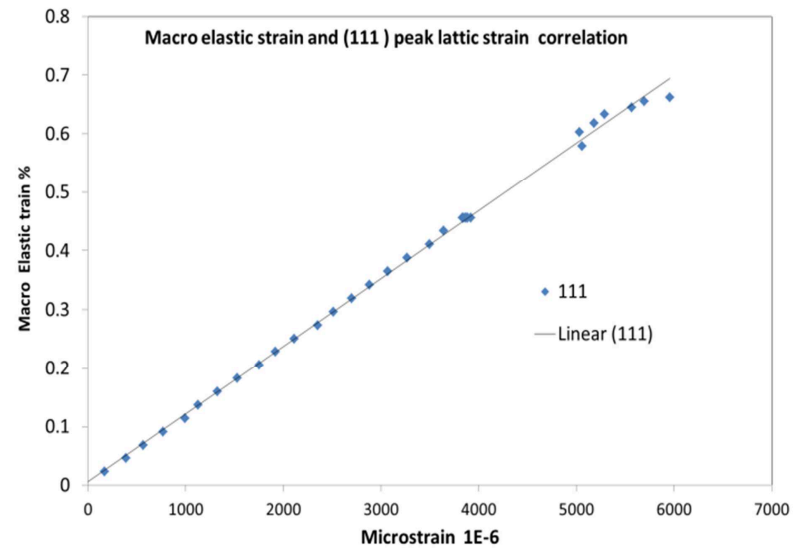

Fig. 5. Correlation of uniaxial macro elastic strain with (111) lattice strain

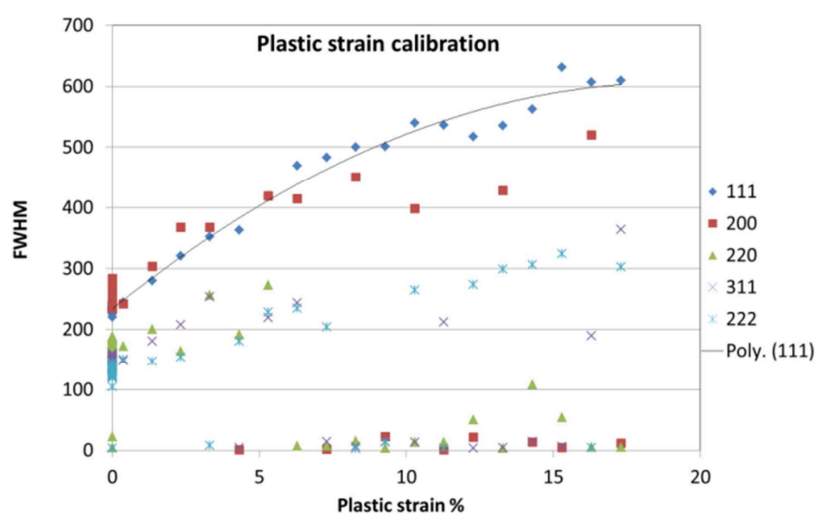

Fig. 6. Correlation of uniaxial plastic strain with full width half maximum (FWHM) of diffraction peaks conditions. 
Neutron Transmission Experiment was carried out on the Engin- $X$ instrument at Rutherford Appleton Laboratory. The sample was placed at $50 \mathrm{~m}$ from the neutron source and $\sim 20 \mathrm{~mm}$ from a neutron counting detector installed directly behind the sample [3]. The neutron source provided short burst of neutrons which were collimated towards the sample position with beam divergence on the scale of 0.5 degree. The energy of each neutron was obtained from its time of flight and thus the transmission spectrum of the sample was measured for each $55 \mu \mathrm{m}$ pixel of the detector, similar to the experiments described in detail in references [3]. The detector used in the experiments consisted of neutron sensitive microchannel plates followed by a $2 \times 2$ array of Timepix readout with $512 \times 512$ pixels, each $55 \times 55 \mu^{2}$. To normalize the intensity variation of the neutron beam the spectrum of the "open beam" was measured first and then used to normalize the transmission spectra of the sample. Multiple Bragg edges were measured at the same time. The data for the Ni bolt sample was acquired over $\sim 4.5$ hours in order to obtain sufficient statistics for the transmission spectra.

\section{Results and Discussion}

\section{Hole drilling (HD) and Neutron Diffraction (ND):}

Fig. 7 illustrates the HD and ND stress measurement results. Given the significant difference in spatial resolution between the HD and ND methods, the stress profiles for the FR condition measured by the two methods shows a reasonable consistency, both showing an increasing tension with depth increased to greater than $0.5 \mathrm{~mm}$. The significant difference between the as-forged and the fillet rolled (FR) results indicates fillet rolling has drastically changed the residual stress field originally induced by bolt-head forging. The bolt in the annealed and fillet rolled condition (A+FR) shows a similar trend of variation to the fillet rolled bolt in both directions, although the former appears more compressive than the latter, indicating residual stress from fillet rolling only is more compressive than that from a combined effect of forging and fillet rolling. The profiles for the solution annealed condition (FR+A) suggest the fillet rolling induced residual stress has been largely mitigated with only a low tension present near the surface. This suggests that post-rolling annealing can relieve the beneficial compressive stress at the fillet and therefore should be avoided in the manufacturing process.
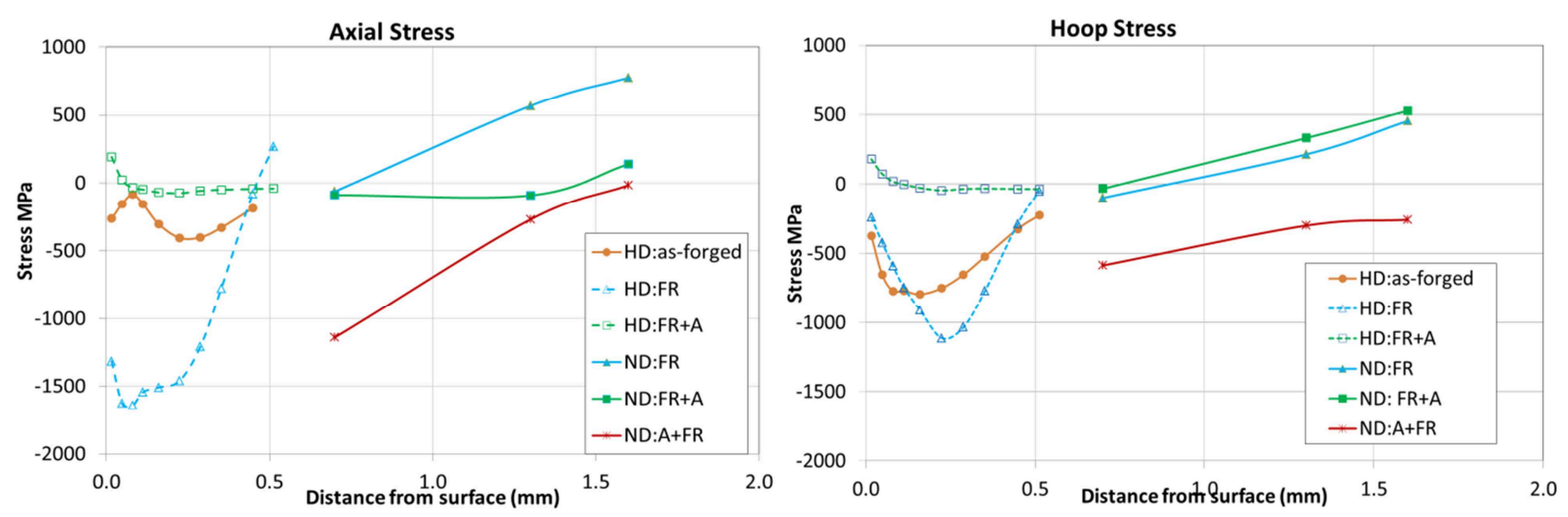

Fig. 7. Hole drilling (HD) and Neutron Diffraction (ND) measured axial and hoop stresses for various bolt conditions: $\mathbf{F R}=$ direct age and fillet rolled (bolt\#3), $\mathbf{F R}+\mathbf{A}=$ fillet rolled and annealed (bolt\#2), $\mathbf{A}+\mathbf{F R}=$ annealed and fillet rolled (bolt\#4).

As opposed to the significant variation of residual stress, the plastic work for the bolts was stable over the whole measured depth, see Fig .8. Moreover, both prior and post rolling annealing have an effect of lowering the plastic work compared to the bolt in the fillet rolled (without being solution annealed) condition. Provided the bolt in fillet rolled condition still retains the plasticity due to the prior cold drawing and forging processes, the relatively high level of plasticity must have been formed in the prior processes rather than in the fillet rolling process. Therefore it can be further 
inferred that the most significant plasticity induced by fillet rolling was formed in a near surface layer which was not covered by the neutron diffraction measurements, i.e., no deeper than $0.7 \mathrm{~mm}$.

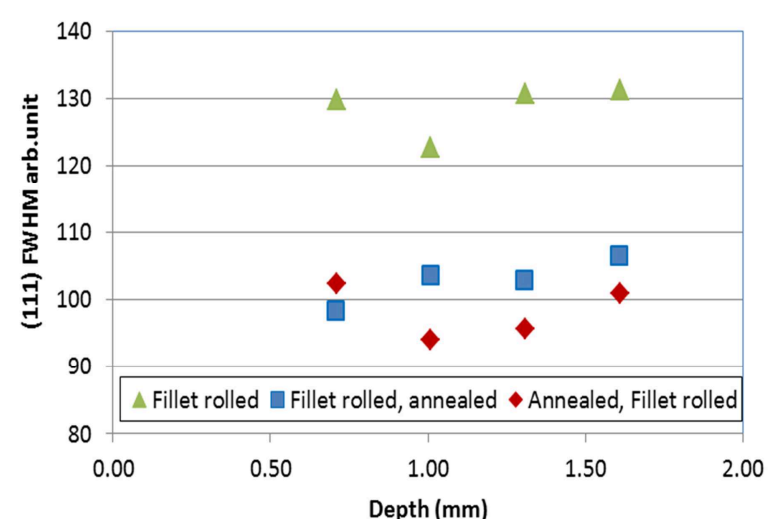

Fig. 8. (111) FWHM as a function of depth for bolts in different conditions

Neutron Transmission (NT): Spatiallyresolved Bragg edges were measured in the transmission experiment [4]. The position of the Bragg edges give an estimate of the average strain in the direction collinear with the incident beam when compared with the unstrained $\mathrm{d}_{0}$ value which was measured at the centre of the shank and the bolt head. In order to achieve sufficient statistics, the spectrum was averaged over 10 pixels, effectively reducing the space resolution to $550 \mu \mathrm{m}$. Only the (111) Bragg-edge was chosen as it generated the smoothest strain profile. Since strain in the bolt is axial symmetry about the
can be assumed functions of radial and axial bolt axis, the hoop and radial strain components can berlonition three-dimensional residual elastic
positions only. This allows a reconstruction of the underlying strain profile (in hoop and radial directions) from the single projected measurement of average transmission strain using a technique known as 'neutron strain tomography' [5 \& 6]. Fig. 9 shows the reconstructed hoop strain distribution in 3D, and Fig. 10 shows the hoop strain depth profiles (NT) extracted from the 3D tomography at $0.8 \mathrm{~mm}$ and $1.3 \mathrm{~mm}$ from the bolt head flange. The two NT profiles show that the hoop strain does not vary between $0.8 \mathrm{~mm}$ and $1.3 \mathrm{~mm}$ axial distance. Compared with the HD strain depth profile which was reconstructed using the residual stress results, the NT measurement is unable to reveal the significant variation in the near-surface due to its lower spatial resolution $(\sim 0.55 \mathrm{~mm})$ than for the HD $(\sim 0.03 \mathrm{~mm})$. The true underlying strain profile can be derived in further work from the NT strain profile through a deconvolution method [7]. Regardless of the difference the NT results verify that that a compressive strain field does exist within the first $0.5 \mathrm{~mm}$ from the surface. Compared with the ND strain profile the NT measurements appear to be more compressive, which may be related to the choice of the wavelength for unstrained material $\left(\lambda_{0}\right)$. Nonetheless both ND and NT measurements show that strain becomes increasingly tensile with increasing depth. A full reconstruction of the residual stresses in three directions would require a second tomographic scan for the axial strain component.

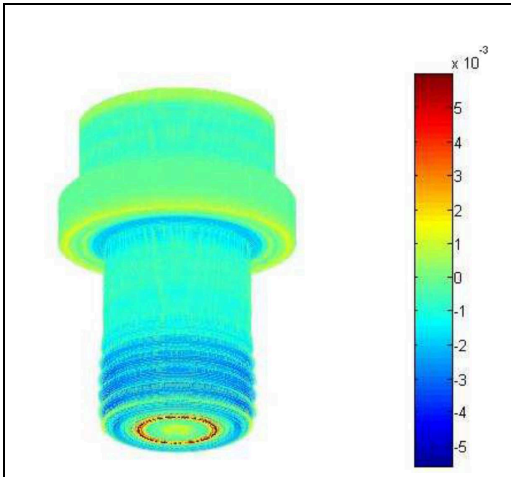

Fig. 9. 3D reconstruction of hoop strain

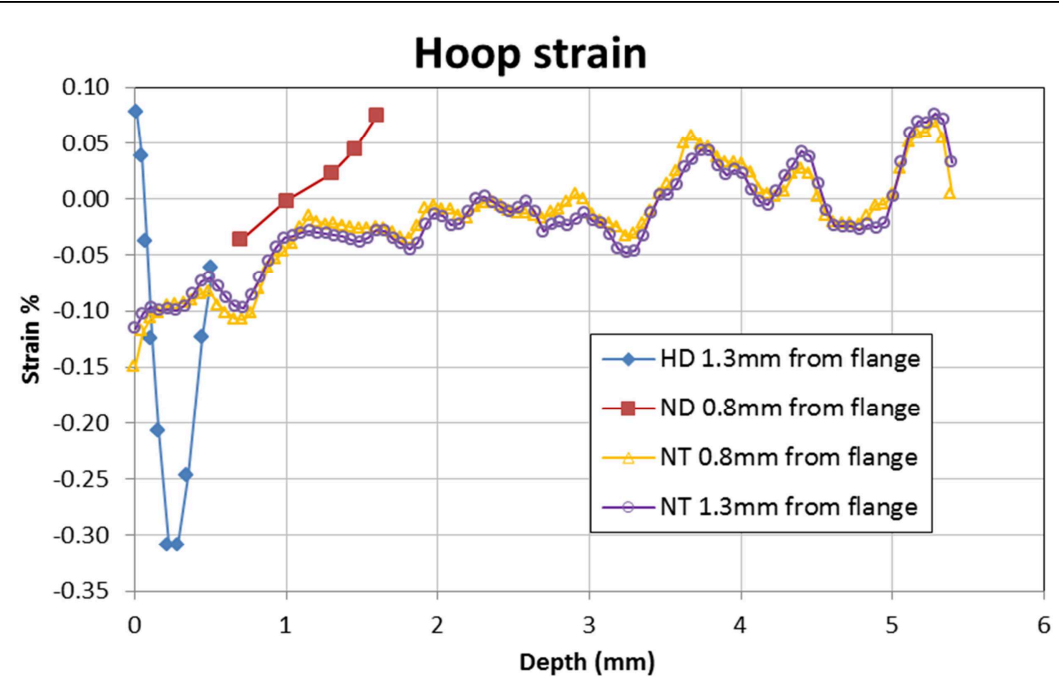

Fig. 10. Hoop strain profiles measured using different techniques: $\mathrm{HD}=$ hole drilling; $\mathrm{ND}=$ neutron diffraction; $\mathrm{NT}=$ neutron transmission 


\section{Conclusions and further work}

Fillet rolling induced compressive residual stress in the first $0.5 \mathrm{~mm}$ in the near-surface with the maximum compressive stress reaching $-1600 \mathrm{MPa}$ in the axial direction of the direct aged ATI 718Plus bolt. Solution anneal after fillet rolling effectively eradicated the compressive stress field and formed a low tension at the surface. Solution annealing prior to fillet rolling removed the preexisting plastic work due to cold drawing and forging, and thus enabled fillet rolling to induce a larger compressive stress field than rolling without prior annealing. The most significant plastic work induced by fillet rolling was estimated to present in a near-surface layer no deeper than 0.7 $\mathrm{mm}$ from the surface.

In the fillet-rolling residual stress assessment, hole drilling offered the best spatial resolution but was limited to the in-plane stresses near the surface. Neutron diffraction was limited by its spatial resolution but it was able to characterise the triaxial strain field in the subsurface. By comparison neutron transmission demonstrated its advantage over neutron diffraction in spatial resolution and scan time. To have a better understanding of the fillet rolling residual stress, and to further explore the capability of neutron transmission, another tomographic scan for the axial strain component shall be performed, the strain profile shall then be processed using a deconvolution method to reveal the true underlying profile, and the 'deconvoluted' strain profiles shall be used to reconstruct the triaxial residual stresses with improved spatial resolution.

\section{Acknowledgement}

The authors would like to thank Stresscraft Ltd for hole drilling residual stress analysis.

\section{References}

[1] Romeyn, A., Bolt Fracture High Pressure Turbine Disk Assembly Pratt \& Whitney Canda PW118A Engine s/n 115120, Australian Transport Safety Bureau Technical Analysis Report $17 / 03$.

[2] Grant, P.V., Lord, J.D. and Whitehead, the Measurement of Residual Stresses by the Incremental Hole Drilling Technique, NPL Measurement Good Practice Guide No. 53, 2006

[3] Tremsin, A.S., et al, "High-resolution strain mapping through time-of-flight neutron transmission diffraction with a microchannel plate neutron counting detector", Strain: An International Journal for Experimental Mechanics, 48 (2012), pp.296-305

[4] Santisteban, J.R, et al, Strain imaging by Bragg edge neutron transmission. Nuclear Instruments and Methods in Physics Research Section A: Accelerators, Spectrometers, Detectors and Associated Equipment, 2002. 481(1-3): p. 765-768

[5] Abbey, B., S.Y. Zhang, F. Hofmann, and K. A.M., Neutron Strain Tomography Using BraggEdge Transmission. International Journal of Materials Research, 103 (2012), No. 2, pp. 234241

[6] Abbey, B., S.Y. Zhang, W. Vorster, and A.M. Korsunsky, Reconstruction of axisymmetric strain distributions via neutron strain tomography. Nuclear Instruments and Methods in Physics Research Section B: Beam Interactions with Materials and Atoms, 270 (2012) pp. 28-35

[7] Xiong, Y.-S. and Withers, P.J., A Deconvolution Method for the Reconstruction of Underlying Profiles Measured using Large Sampling Volumes, Journal of Applied Crystallography, 39 (2006), pp 410-424 